\title{
Migrations to Europe: Old and New Problems of Conflict and Resolution.
}

\author{
Thomas Heise; Co-Chair Section Conflict Management \& Resolution WPA; MD PhD PhD
}

Author of: Kulturen der Menschheit: Woher und wohin? ISBN-13: 978-3826059735

Cultures of Mankind: Whence and Wither? Interdisciplinary Perspectives of our Past.

Method: A review of the last decade's journals and literature revealed the present state of art (lit. with the author and in the book)

Introduction: A division of times had to be made into the period before homo sapiens, the paleolithic and the neolithic times as well as the modern ones. MIGRATIONS BEFORE HOMO SAPIENS - from „national to international“: Homo Australopithecus Afarensis (Lucy) $3.2 \mathrm{M}$; Homo Lomekwi 3.3 M (15 kilo tools); Homo Habilis >> Homo Erectus 2.4 M climate refugee: (Longgudong/Hubei-China 2.0 M, > Dmanissi/Georgia 1.8 $\mathrm{M}$, > Pirro Nord/South Italy 1.7-1.3 M, > Orce/Spain 1.8-1.4 M, > Sangiran/Java-Indonesia 1.5-0.9 M, > Flores/Indonesia 0.9 M, > Zhoukoudian/Peking, > Atapuerca/Spain 1.1-0.7 M, > Heidelberg/Germany 0.6 M, > Calico/California-USA 0.2 M). - $\rightarrow$ Homo Denisova (Siberia 0.4? 0.22-0.13 M); Homo Neanderthalensis (Swanscombe/GB 0.4 M); At least a dozen more local Homo species parallel to homo sapiens, which all mixed genetically to form us somewhat different in the concerned areas and spreading this by migration.

CONTRADICTING DISCOVERIES? „Moyjil Site“ in South-West Victoria: Fireplace 120.000 years old. The oldest human bones (male) of Sahul from Mungo Lake $62.000 \pm 6.000$ years ago. - The probability of persisting on Sahul once reached, requires at least 1.400 people to ensure surviving.

HOW ABOUT THE JOURNEY TO THE CONTINENT OF EUROPE? To Greece: Apidima 2: 170 thousand years ago with Neanderthal-like morphological pattern. Apidima 1 dates to more than 210 thousand years ago, presenting a mixture of modern human and primitive features.

It was looked for the possible conflicts and their related management in all of these mentioned as well as modern periods.

Results:

\section{CONFLICTS and MANAGEMENT:}

Pre- \& Paleolithic times: The skull of an Australopithecus showed 2 fractureholes in which the end of an antelopes foreleg found nearby was fitting perfectly well. Forensic reveals in Cioclovina evidence of interpersonal violence ca. 30,000 years ago. Same period: in Sungir (Russia) skeletons which show similar signs of violence. One Thoracic vertebral body was definitely injured by a spearhead. In 21 mobile forager bands they examined 148 cases of lethal aggression: only personal conflicts with bad outcome. No war between groups. 4 hour working days, no tax.

The „Neolithic Revolution“ brought us: Cities for more people; First specializations in their jobs and creating effective teamwork; Keeping more cattle; Harvesting, processing and storing more crops \& cereals for bad days and seasons as well as climate troubles; Specific cultures which distinguished one civilisation from another; Political and spiritual leaders; Power differences by political, spiritual and/or financial reasons; The desire for possessing more (... cattle = „war“ in Sanskrit); Townwalls to defend one's possessions; Military for defense and for attack; Civilisation with scripture to write down important events and create history as well as social and spiritual rules.

The „Industrial Revolution“ brought us: More specialized jobs; Less working happiness because of small working process units where you are disconnected to the end result; Time stress; More power differences by political, spiritual, social and/or financial reasons; The development of advanced technical and chemical weapons for WW I \& II; Deepened sciences into the details; The mechanics derived idea of creating by education a new kind of human (socialist, communist, nationalist, islamist, ...); Alienation from nature which is only seen as a resource to be exploited; United Nations and International Red Cross/Halfmoon to avoid violent conflicts, to intermediate, to avoid epidemies, to counteract the atrocities of the armed conflicts and bad health.

The „Postindustrial Revolution“ brought us: The petro- \& chemicalisation of the world, polluting everything because of mere profitorientation instead of limiting to the real necessities by keeping a sane balance to restore nature; Less collective oriented societies and more individualistic - narcicisstic tendencies; Global power for very few outside of the range of a reciproque responsibility; Standardization in working process and life disregarding individual needs; Technical means for the possibility of, and partly started, overwhelming control of the normal citizen; Counselling \& psychotherapy, to counteract at least some of the pathological tendencies for those who suffer by it (burnout, depression, anxiety, PTSD, addiction), not those who cause it; A suffering world society, because they are squeezed out, for the sake of other people's profit; Still a world full of hunger and disease and many armed conflicts; Loosing the overwiew by too many details to hide the great direction.

What do we need? - „Ethical revolution“! Euphemistic answers ... : Better work-life balance; More lifelong education everywhere for everybody; Only useful and resilient progress; Return to local balances of power in many fields and reduction of bureaucracy; Limit to worldwide power aggregation of companies and financial resources; Global responsibility for nature, not by single powerful persons, companies or countries misusing their possibilities, Reduce the power of statistics, enhance the phantasy and intuition in education, work and research; More time for emotional relatedness and searching for understanding.

\section{Discussion:}

Migrations started by climate reasons and will end by those. In between conflicts of power and economical reasons have been dominant as its source. Problems of migration, their conflicts and resolution have always been linked to the structure of the concerned society. Nowadays society must change, to give a better conflict management and resolution a real chance. 